\title{
Development of Polypropylene-based Thermoplastic Elastomers with Crumb Rubber by Dynamic Vulcanization: A Potential Route for Rubber Recycling
}

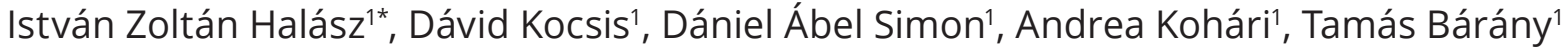 \\ ${ }^{1}$ Department of Polymer Engineering, Faculty of Mechanical Engineering, Budapest University of Technology and Economics, \\ H-1111 Budapest, Müegyetem rkp. 3., Hungary \\ * Corresponding author, e-mail: halaszi@pt.bme.hu
}

Received: 01 March 2019, Accepted: 26 June 2019, Published online: 23 December 2019

\begin{abstract}
In our current paper the preparation and properties of thermoplastic elastomer produced by dynamic vulcanization is presented and discussed. We dynamically vulcanized natural and styrene butadiene rubber (NR/SBR) phase by continuous extrusion. Dispersion and in-situ vulcanization of the rubber phase occurred simultaneously in a co-rotating twin screw extruder. We used a random polypropylene copolymer (rPP) as the thermoplastic matrix and untreated crumb rubber (CR) to partially substitute the neat fresh rubber in order to check whether this is a potential recycling route for waste rubber products. We studied the effect of various rubber formulations, various processing conditions (screw speed and configuration) and various CR particle size distributions by characterizing the mechanical performance of the thermoplastic dynamic vulcanizates (TDVs) with tensile and hardness tests and their morphology by evaluating SEM micrographs taken from the fracture surfaces of the tensile specimens. The results showed that increasing screw speed and more high-shear elements in the screw setup led to a finer dispersion of the rubber phase, resulting in improved mechanical properties. The ultimate tensile properties of the best TDVs reached $20.5 \mathrm{MPa}$ in tensile strength and $550 \%$ in strain at break. However, partial replacement of the fresh rubber with untreated CR caused a significant deterioration in mechanical properties, due to poor adhesion between the CR particles and the matrix and rubber. This suggests that some kind of pre-treatment (e.g. by microwave or other devulcanization techniques) is necessary to enhance the surface activity of the CR particles.
\end{abstract}

\section{Keywords}

thermoplastic dynamic vulcanizate, polypropylene, natural rubber, styrene butadiene rubber, crumb rubber, ground tire rubber, rubber recycling

\section{Introduction}

One of the major ecological headaches of our age is the expanding amount of polymeric waste, among which chemically crosslinked rubbers represent an even more challenging part. This is due to their 3D molecular structure, which makes them unsuitable for the classic recycling techniques based on remelting and remolding, which are widely used for plastics. One viable alternative seems to be grinding the rubber waste and using the resulting crumb rubber (CR) in various ways, e.g., as a filler in thermoplastic and thermoset resins [1] and rubbers [1,2]. One example is to embed this CR into a preferably thermoplastic polymeric matrix, which makes it possible to mold the CR into a new product. Another approach for these ecological and environmental issues is the substitution of crosslinked rubbers in certain application fields with thermoplastic elastomers having similar elasticity and high reversible deformability compared to traditional plastics, thus combining the desired mechanical behavior with good processability and reprocessability. These materials are termed thermoplastic elastomers, among which TDVs play an important role. These materials are composed of finely dispersed dynamically cured rubber particles and continuous thermoplastic matrix (commonly in polyolefins like polypropylene [3]). The term "dynamically cured" refers to the fact that the curing of the rubber phase occurs simultaneously with its dispersion during intensive mixing [3, 4]. Basic research in the field of thermoplastic vulcanizates began almost four decades ago. Several thermoplastic-rubber combinations were investigated, and the following conclusions were drawn: (i) the surface free energy of the thermoplastic and the rubber should 
be nearly identical, (ii) crosslink density of the rubber phase should be high, (iii) the thermoplastic matrix should be semicrystalline $[5,6]$. These findings culminated in the patenting and commercialization of polyolefin-based TDVs, with PP as matrix and ethylene propylene diene terpolymer (EPDM) as the rubber phase. However, as the importance of the aforementioned economic and ecological aspects of polymeric waste management grew, researchers started to focus on various material combinations. This was propelled by the idea of utilizing waste rubber as a feedstock for TDV production, therefore these publications were focused on rubbers used by the tire industry (NR, IR, BR, SBR), which is responsible for $70 \%$ of overall rubber consumption. A great variety of thermoplastics can serve as matrix material, but most research activity has been focused on polyolefins, such as low density polyethylene (LDPE) [7, 8], linear low density polyethylene (LLDPE) [9], high density polyethylene (HDPE) [10-12], and polypropylene (PP) [13, 14].

Moreover, the sustainability of these materials can be further enhanced by the partial replacement of the fresh rubber by treated (e.g. devulcanized by some devulcanization technique $[1,15,16]$ or untreated CR. However, the addition of untreated CR usually leads to deteriorated mechanical performance of the resulting TDV.

This paper focuses on the optimization of the processing technique and rubber phase formulation of PP based TDVs for further development with the utilization of microwave devulcanized CR produced from the tread of truck tires to fulfil our final goal: partially replace the fresh rubber phase with microwave treated CR. Therefore, we evaluated natural rubber (NR) and styrene butadiene rubber (SBR)based formulations (typical rubbers of truck tire treads) and the effects of different carbon blacks in the presence and absence of a plasticizer oil. Two types of untreated CR with different average particle sizes and particle size distributions were used. The effect of microwave-treated CR will be in the scope of our upcoming work. One of the tested model rubbers contained pyrolytic carbon black recovered from passenger car and truck tires by pyrolysis as a reinforcing filler. We included it to check the feasibility of such carbon blacks, thus putting special emphasis on sustainability in this paper.

\section{Materials and methods}

We used random polypropylene (rPP) copolymer(TIPPLEN R959A MOL Petrochemicals Co. Ltd, Budapest, Hungary, MFR $\left(230{ }^{\circ} \mathrm{C}, 2.16 \mathrm{~kg}\right): 45 \mathrm{~g} / 10 \mathrm{~min}$, tensile strength at yield: $30 \mathrm{MPa}$, tensile strain at yield: $12 \%$, tensile data provided by the supplier is based on tensile tests according to ISO $527-1,2$ performed on injection molded specimens produced according to ISO 1873-2) as thermoplastic matrix. As rubber, natural rubber was used (NR, NR TSR 10 Sud Comoe Caoutchuc, Aboisso, Ivory Coast) and styrene-butadiene rubber (SBR, SBR 1502, SKS-30 ARKPN, JSC Sterlitamak Petrochemical Plant Sterlitamak, Russia, Mooney viscosity $\left(\mathrm{ML}, 1+4,100{ }^{\circ} \mathrm{C}\right)$ : $48-58$, bound styrene content: $2225 \mathrm{wt} \%$ ). Crumb rubbers were waterjet-milled ground tire rubbers (CR, Hungarojet Ltd., Budapest, Hungary). Two types of CR were used, ultrafine $\mathrm{CR}(\mathrm{uCR})$ and fine $\mathrm{CR}(\mathrm{CR})$ with average particle sizes of $30 \pm 12 \mu \mathrm{m}$ and $173 \pm 9 \mu \mathrm{m}$, respectively.

The other components of the model rubber formulations and their suppliers were: zinc oxide $(\mathrm{ZnO}, \mathrm{ZnO}$ 99.7 \%, Werco Metal, Zlatna, Romania), stearic acid (StA, Radiacid 0444, Oleon, Ertvelde, Belgium) N550 carbon black (Omsk Carbon Group, Omsk, Russia), pyrolytic carbon black ( $\mathrm{pCB}$, detailed characterization can be found in [17]) naphthenic oil (NOil, Tudalen 4353, H\&R Group, Hamburg, Germany), N-Cyclohexyl-2benzothiazolesulfenamide (CBS, Rhenogran CBS, Rhein Chemie, Mannheim, Germany), tetramethyl thiuram disulfide (TMTD, Vulkacit Thiuram, Lanxess, Cologne, Germany) and sulphur (S, Powder Sulphur, Russia). Table 1 lists the formulation of each model rubber compound.

The rubber ingredients were mixed with a laboratory two-roll mill (Labtech LRM-SC-110, Labtech Engineering Co. Ltd., Samutprakarn, Thailand). Fig. 1 shows the curing curves of the rubber compounds at $180{ }^{\circ} \mathrm{C}(1.67 \mathrm{~Hz}$ and $1^{\circ}$ amplitude, measured on a MonTech D-RPA 3000 Dynamic Rubber Process Analyzer, MonTech, Buchen, Germany).

The curing parameters determined from the curves are listed in Table 2.

Table 1 Formulations of the fresh rubber compounds

\begin{tabular}{cccccc}
\hline \multicolumn{2}{c}{ R1 } & \multicolumn{3}{c}{ R2 } & \multicolumn{2}{c}{ R3 } \\
\hline SBR & 70 & SBR & 70 & SBR & 70 \\
NR & 30 & NR & 30 & NR & 30 \\
pCB & 60 & N550 & 60 & N550 & 60 \\
ZnO & 5 & ZnO & 5 & NOil & 30 \\
StAc & 2 & StAc & 1 & ZnO & 5 \\
CBS & 3 & CBS & 1.5 & StAc & 1 \\
S & 0.5 & TMTD & 1.5 & CBS & 1.5 \\
& & S & 1.5 & TMTD & 1.5 \\
& & & & S & 1.5 \\
\hline
\end{tabular}




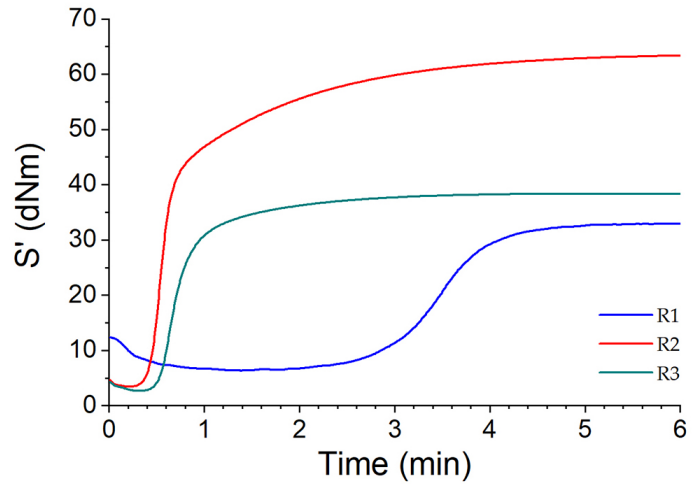

Fig. 1 Curing curves of the fresh rubber compounds at $180^{\circ} \mathrm{C}$

Table 2 Curing parameter of the fresh rubber compounds

\begin{tabular}{lccccc}
\hline & $\begin{array}{c}M_{L} \\
\mathrm{dNm}\end{array}$ & $\begin{array}{c}M_{H} \\
\mathrm{dNm}\end{array}$ & $\begin{array}{c}t_{10} \\
\mathrm{~min}\end{array}$ & $\begin{array}{c}t_{70} \\
\mathrm{~min}\end{array}$ & $\begin{array}{c}t_{90} \\
\mathrm{~min}\end{array}$ \\
\hline $\mathrm{R} 1$ & 6.31 & 33.02 & 2.74 & 3.42 & 4.16 \\
$\mathrm{R} 2$ & 3.44 & 63.49 & 0.45 & 0.90 & 2.37 \\
$\mathrm{R} 3$ & 2.65 & 38.34 & 0.54 & 0.85 & 1.52 \\
\hline
\end{tabular}

Prior to compounding, fresh rubber mixes were shaped on a single screw extruder (Labtech 25-30C, Labtech Engineering Co. Ltd., Samutprakarn, Thailand) at a screw speed of $40 \mathrm{rpm}$ and zone temperatures between $95^{\circ} \mathrm{C}$ and $105^{\circ} \mathrm{C}$ ), and a single rubber filament was produced with a diameter of $3 \mathrm{~mm}$. This ensured the precise and reproducible dosing of the rubber during TDV production.

The rubber was dynamically vulcanized during compounding on a modular co-rotating twin screw extruder (Labtech LTE 26-44, Labtech Engineering Co. Ltd., Samutprakarn, Thailand) with a temperature profile consisting of zone temperatures between $160{ }^{\circ} \mathrm{C}$ and $180{ }^{\circ} \mathrm{C}$. Base screw speed was $60 \mathrm{rpm}$, but tests with 120 and $180 \mathrm{rpm}$ screw speed were also carried out to profile the effect of different screw speeds. The rubber was dosed by feeding the rubber filament continuously into the hopper of the twinscrew extruder. rPP and the rubber filament were fed through the hopper $(\mathrm{H})$ of the twin-screw extruder simultaneously.

The effect of different screw configurations was also tested. Fig. 2 shows different screw configurations. Two of the three kneading blocks on Screw "S2" are positioned closer to the hopper. The concept behind it was to achieve intensive mixing and kneading at a relatively early stage of the dynamic vulcanization of the rubber phase, which may lead to finer dispersion and an improvement in the mechanical performance of the resulting TDVs. A conveying element with reverse flight at the middle kneading block, increased pressure and decelerated melt flow. This way, the preceding kneading block kneaded/sheared the compound even more

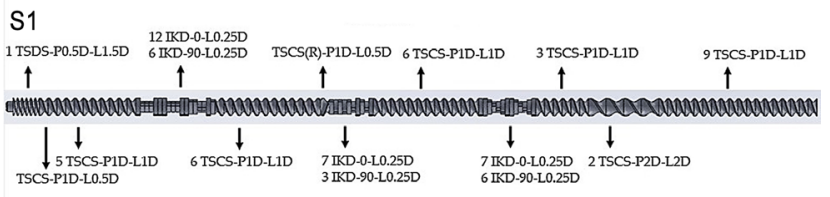

S2

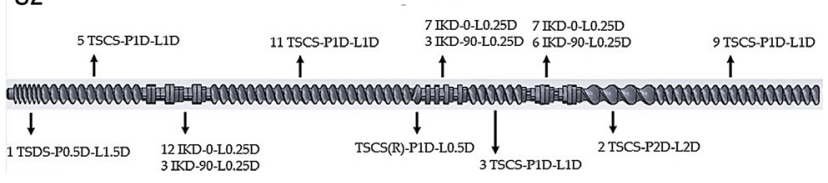

Fig. 2 Screw configurations: (a) Screw configuration S1 (b) Screw configuration S2. Designation of the screw modules: (D stands for the diameter of the screw): TSCS-P1D-L1D: twin-start conveying screw, pitch 1D, length 1D; TSCS(R)-P1D-L1D: twin-start conveying screw (reverse flight), pitch 1D, length 1D; TSCS-P2D-L2D: twin-start conveying screw, pitch $2 \mathrm{D}$, length $2 \mathrm{D}$; IKD-0-L0.25D: individual kneading disc, length $0.25 \mathrm{D} 0^{\circ}$ angle; IKD-90-L0.25D: individual kneading disc, length $0.25 \mathrm{D} 90^{\circ}$ angle (each kneading disc can be rotated and positioned in $60^{\circ}$ steps on the screw, so utilizing a $0^{\circ}$ and a $90^{\circ}$ kneading element allowed us to build kneading blocks with individual discs having a $30^{\circ}$ angle difference compared to the neighboring blocks: $0^{\circ}, 60^{\circ}, 120^{\circ} ; 180^{\circ} ; 240^{\circ}$ and $300^{\circ}$ was achieved with discs with a $0^{\circ}$ angle, while $30^{\circ}, 90^{\circ}, 150^{\circ}, 210^{\circ}, 270^{\circ}, 330^{\circ}$ was achieved with discs with a $90^{\circ}$ angle); TSDS-P0.5D-L1.5D: twin-start discharge screw, pitch $0.5 \mathrm{D}$, length $1.5 \mathrm{D}$

intensively. At the end of the screw, a conveying element with $1.5 \mathrm{D}$ length and $0.5 \mathrm{D}$ pitch was used to increase the pressure for more homogenous and more uniform output.

The applicability and the effect of various CRs in TDV production were studied by partial replacement of the fresh rubbers with crumb rubber in a ratio of $50 \mathrm{wt} \%$ (meaning $25 \mathrm{wt} \%$ fresh rubber and $25 \mathrm{wt} \% \mathrm{CR}$ content in the final TDV). The designation terminology of the TDVs is explained in Table 3.

From the compounds ISO 3167 A type dumbbell specimens were injection molded with an Arburg Allround Advance 370S 700-290 injection molding machine (Arburg Ltd. Lossburg, Germany). The related parameters were: barrel temperature range: $170-190{ }^{\circ} \mathrm{C}$, mold temperature: $30{ }^{\circ} \mathrm{C}$, injection speed: $50 \mathrm{~cm}^{3} / \mathrm{s}$, shot volume: $44 \mathrm{~cm}^{3}$ and holding pressure: 350 bar.

Table 3 Designation terminology of the tested TDVs

\begin{tabular}{ccccc}
\hline $\begin{array}{c}\text { Fresh rubber } \\
\text { content } \\
\mathrm{wt} \%\end{array}$ & $\begin{array}{c}\text { Rubber } \\
\text { formulation }\end{array}$ & $\begin{array}{c}\text { Screw } \\
\text { configuration } \\
-\end{array}$ & $\begin{array}{c}\text { Screw } \\
\text { speed } \\
\text { rpm }\end{array}$ & $\begin{array}{c}\text { CR content } \\
\text { and type } \\
\mathrm{wt} \%,-\end{array}$ \\
\hline 40 & $\mathrm{R} 1$ & $\mathrm{~S} 1$ & 60 & \\
50 & $\mathrm{R} 2$ & $\mathrm{~S} 2$ & 120 & \\
60 & $\mathrm{R} 3$ & & 180 & \\
25 & & & & $25 \mathrm{CR}$ \\
& & & & $25 \mathrm{uCR}$ \\
\hline
\end{tabular}


The hardness of the injection molded specimens was tested according to the ISO 868 Shore D method on a Zwick H04.3150.000 hardness tester (Zwick GmbH., Ulm, Germany). Each compound was tested 10 times, followed by the calculation of average and standard deviation.

The tensile mechanical properties of the compounds were tested according to the ISO 527 standard on a Zwick Z250 universal testing machine with a $20 \mathrm{kN}$ load cell (Zwick GmbH., Ulm, Germany) at room temperature at a crosshead speed of $100 \mathrm{~mm} / \mathrm{min}$. The average and standard deviation of the tensile strength and elongation at break were determined with 5 tests on each compound.

The morphology of the TDVs was characterized with SEM micrographs. We took SEM images of the fracture surfaces of the tensile specimens with a Jeol JSM 6380 LA scanning electron microscope (Jeol Ltd., Tokyo, Japan). Prior to investigation, the surfaces of the specimens were sputter coated with gold.

\section{Results and discussion}

The tensile mechanical properties of the produced TDVs were tested and evaluated. Fig. 3 shows the characteristic tensile curves of the rPP, the fresh rubbers and the different TDVs.

Results show that TDVs containing R1 rubber show a more rPP-like tensile behavior with a well-defined yield point, but TVDs with R2 and R3 rubber show rubberier tensile behavior. The tensile properties and hardness of the rubber compounds are shown in Table 4. Rubbers R2 and R3 outperformed rubber R1 containing pyrolytic black in terms of mechanical performance. This may suggest that the activity of this carbon black is lower than that of N550 used in the R2 and R3 compounds, although curing systems are not fully identical. We modified the curing system to reduce the curing time of the rubber in order to achieve better curing during extrusion compounding. As expected, the addition of $30 \mathrm{phr}$ naphthenic oil resulted in decreasing tensile strength and hardness and increasing elongation at break.

\subsection{The effect of different rubber formulations and rubber contents}

Fig. 4 and Table 5 show the tensile properties and hardness of the TDVs with different base rubbers and rubber contents. TDVs with rubber R2 had the best performance, but elongation at break results show a different trend among the different compositions. With a rubber content of $50 \mathrm{wt} \%$ and $60 \mathrm{wt} \%$, TDVs containing R1 and R3 rubbers outperformed the TDV with R2 rubber. R1 rubber provided the best results in terms of elongation at break, which may

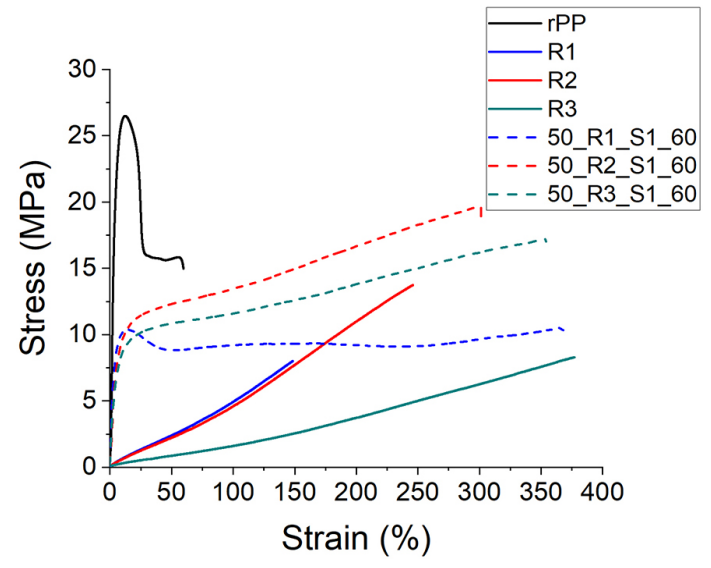

Fig. 3 Characteristic tensile curves of the rPP, rubber (R2) and TDVs

Table 4 Mechanical properties of the base rubber compounds

\begin{tabular}{ccccc}
\hline & $\begin{array}{c}\text { TS } \\
\text { MPa }\end{array}$ & $\begin{array}{c}\text { EB } \\
\%\end{array}$ & $\begin{array}{c}\text { M100 } \\
\text { MPa }\end{array}$ & $\begin{array}{c}\text { HSD } \\
\text { ShD }^{\circ}\end{array}$ \\
\hline R1 & $8.6 \pm 0.9$ & $157 \pm 14$ & $5.3 \pm 0.4$ & $39.0 \pm 2.8$ \\
R2 & $13.8 \pm 0.2$ & $243 \pm 5$ & $5.2 \pm 0.1$ & $32.0 \pm 3.2$ \\
R3 & $9.1 \pm 1$ & $386 \pm 23$ & $1.8 \pm 0.2$ & $20.1 \pm 1.6$ \\
\hline
\end{tabular}
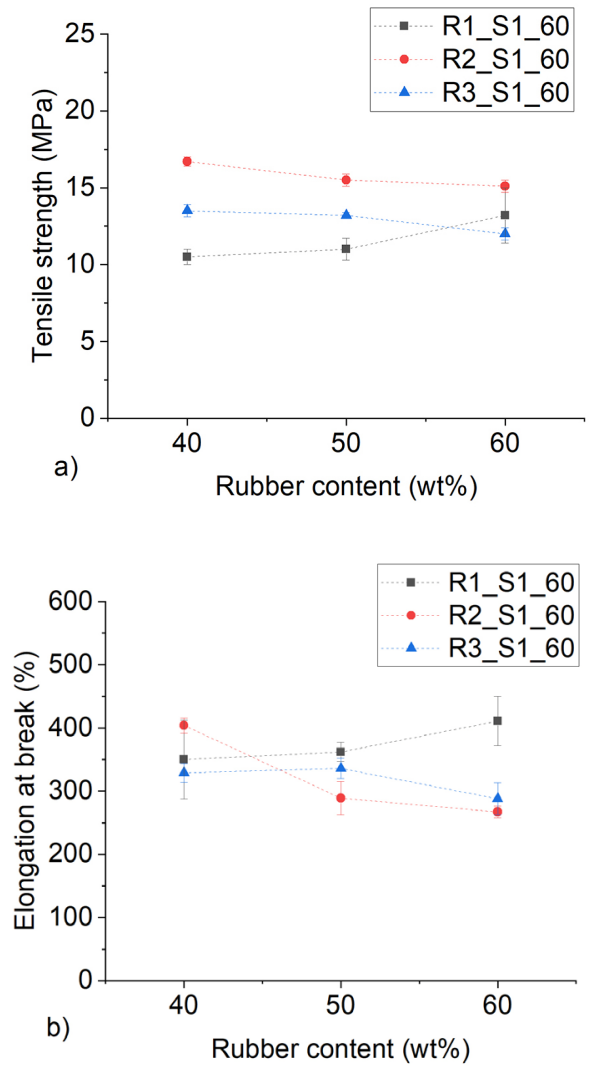

Fig. 4 Tensile strength (a) and elongation at break (b) of TDVs with different rubber formulations and content

be explained by the fact that among the tested rubbers, it had the highest viscosity (cf. Fig. 1 and note that the minimum torque values represent viscosity differences among 
Table 5 M100, M300 and Shore D hardness values of the TDVs with different rubber formulation and content

\begin{tabular}{lccc}
\hline & $\begin{array}{c}\text { Screw speed } \\
\mathrm{rpm}\end{array}$ & $\begin{array}{c}\text { M100 } \\
\mathrm{MPa}\end{array}$ & $\begin{array}{c}\text { HSD } \\
\mathrm{ShD}^{\circ}\end{array}$ \\
\hline \multirow{2}{*}{ R1_S1_60 } & 40 & $9.3 \pm 0.2$ & $54 \pm 1$ \\
& 50 & $8.7 \pm 0.2$ & $54 \pm 2$ \\
& 60 & $8.7 \pm 8.7$ & $48 \pm 1$ \\
\hline \multirow{2}{*}{ R2_S1_60 } & 40 & $14.5 \pm 0.2$ & $57 \pm 1$ \\
& 50 & $13.8 \pm 0.3$ & $53 \pm 1$ \\
& 60 & $13.4 \pm 0.1$ & $51 \pm 1$ \\
\hline & 40 & $12.0 \pm 0.1$ & $51 \pm 1$ \\
& 50 & $11.7 \pm 0.1$ & $49 \pm 1$ \\
& 60 & $11.2 \pm 0.1$ & $47 \pm 0$ \\
\hline
\end{tabular}

the uncured rubber compounds). This high viscosity resulted in higher shear loads during mixing, resulting in a finer dispersion of the rubber phase. A comparison of the tensile performance of $\mathrm{R} 2$ and $\mathrm{R} 3$ rubber-based TDVs suggests that the oil in the rubber compound plasticized the whole TDV, lowering its tensile strength, but improving its elongation at break. This effect is further corroborated by the hardness test results, showing noticeably lower values of TDVs containing R3 rubber (cf. Table 5).

\subsection{Effect of screw configuration}

The tensile properties and hardness of the TDVs produced with different screw configurations are summarized in Table 6. The results show that altering screw configuration in order to increase shear during compounding has a clearly positive effect on the mechanical properties of the resulting TDVs.

Both tensile strength and elongation at break improved with screw configuration S2, which can be explained by the finer dispersion of the rubber phase; this resulted in finer morphology of the resulting TDVs.

\subsection{The effect of screw speed}

The tensile properties and hardness of the TDVs produced with different screw speeds are summarized in Fig. 5 and Table 7. The effect of different screw speeds was tested on both screw configurations and R2 and R3 rubbers.

Results show that increasing shear load by increasing screw speed has the same positive effect as increasing shear load by the modification of screw configuration. Both tested compounds showed significant improvement in tensile mechanical behavior. Compounds with R3 rubber and a modified S2 screw configuration gave the best results, with a tensile strength of more than $20 \mathrm{MPa}$ and elongation
Table 6 Mechanical properties of the TDVs produced with various screw configurations

\begin{tabular}{lcccc}
\hline & $\begin{array}{c}\text { TS } \\
\mathrm{MPa}\end{array}$ & $\begin{array}{c}\text { EB } \\
\%\end{array}$ & $\begin{array}{c}\text { M100 } \\
\mathrm{MPa}\end{array}$ & $\begin{array}{c}\text { HSD } \\
\mathrm{ShD}^{\circ}\end{array}$ \\
\hline 50_R3_S1_60 & $13.2 \pm 0.2$ & $336 \pm 15$ & $11.7 \pm 0.1$ & $51 \pm 1$ \\
50_R3_S2_60 & $17.6 \pm 0.1$ & $381 \pm 10$ & $12.1 \pm 0.2$ & $54 \pm 2$ \\
\hline
\end{tabular}
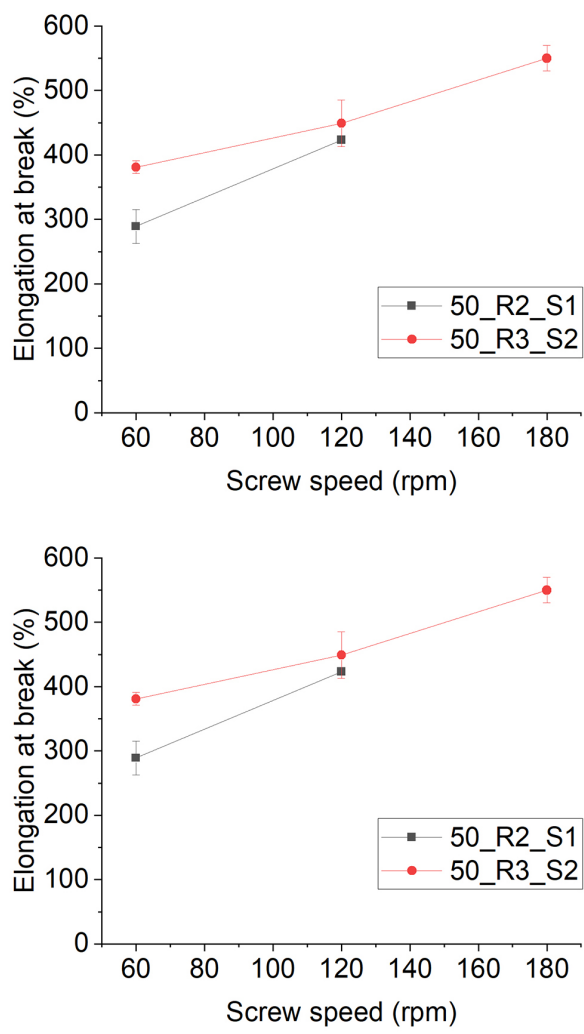

Fig. 5 Tensile strength (a) and elongation at break (b) of TDVs produced with various screw speeds

Table 7 M100, M300 and Shore D hardness values of the TDVs produced with different screw speeds

\begin{tabular}{lccc}
\hline & $\begin{array}{c}\text { Screw speed } \\
\text { rpm }\end{array}$ & $\begin{array}{c}\text { M100 } \\
\text { MPa }\end{array}$ & $\begin{array}{c}\text { HSD } \\
\text { ShD }^{\circ}\end{array}$ \\
\hline 50_R2_S2 & 60 & $13.8 \pm 0.3$ & $57 \pm 1$ \\
& 120 & $13.9 \pm 0.1$ & $59 \pm 1$ \\
\hline \multirow{2}{*}{ 50_R3_S2 } & 60 & $12.1 \pm 0.2$ & $52 \pm 1$ \\
& 120 & $13.6 \pm 0.2$ & $54 \pm 2$ \\
& 180 & $13.6 \pm 0.4$ & $54 \pm 2$ \\
\hline
\end{tabular}

at break over $500 \%$. Note that these values are comparable to the performance of commercially available TDVs.

\subsection{The effect of CR addition}

The tensile properties and hardness of the TDVs containing various crumb rubbers are summarized in Table 8 . The tensile mechanical performance of the TDVs containing 
CR are strikingly poor compared to the TDVs containing only fresh rubber. Ultrafine CR particles (uCR), however, led to better tensile results.

This effect of CR can be explained if the fracture surfaces of the specimens are inspected. Fig. 6 shows the SEM micrographs of the fracture surface of TDVs containing 0 and $25 \mathrm{wt} \%$ of uCR. Samples containing $\mathrm{CR}$ revealed poor interfacial adhesion between $\mathrm{CR}$ particles and the matrix, thus leading to stress concentration around CR particles. This resulted in macroscopic failure at lower loads (compared to TDVs with fresh rubber, finer rubber dispersion and better interfacial adhesion between the distinct phases).

\section{Conclusion}

Based on the results of our work, the following conclusions can be drawn:

- increasing shear load (by altering screw configuration and increasing screw speed) during compounding is highly beneficial regarding the mechanical properties on the final TDV. This may be attributed to the refined dispersion of the rubber phase in the PP leading to improving interaction between the phases,

- fully replacing the fresh rubber by neat, untreated CR is not feasible; compounds with CR showed astonishingly poor performance. This can be the result the relatively large CR particle size and the inactivity of the CR particle surface due to its crosslinked structure which also hindered the fragmentation of the CR particles during compounding. Fragmentation of the CR particles could have led to finer CR particle sizes which would probably have a positive effect on mechanical performance,

- although utilizing CR as a feedstock for TDV production is not pointless, some kind of pre-treatment (e.g. microwave devulcanization) seems necessary to enhance interface adhesion between the CR particles and the PP/rubber. Devulcanization of the CR can also lead to better plasticity of the CR phase, which may result in fragmentation of the $\mathrm{CR}$ particles during compounding, leading to smaller particle sizes of $\mathrm{CR}$, further enhancing mechanical properties.
Table 8 Mechanical properties of the TDVs produced with various crumb rubbers

\begin{tabular}{lcccc}
\hline & $\begin{array}{c}\text { TS } \\
\mathrm{MPa}\end{array}$ & $\begin{array}{c}\mathrm{EB} \\
\%\end{array}$ & $\begin{array}{c}\mathrm{M} 100 \\
\mathrm{MPa}\end{array}$ & $\begin{array}{c}\text { HSD } \\
\mathrm{ShD}^{\circ}\end{array}$ \\
\hline 50_R3_S2_120 & $19.7 \pm 0.5$ & $449 \pm 36$ & $13.6 \pm 0.2$ & $54 \pm 2$ \\
25_R3_ & & & & \\
S2_120_25CR & $11.1 \pm 0.2$ & $34 \pm 3$ & - & $47 \pm 3$ \\
25_R3_ & & & & \\
S2_120_25uCR & $11.5 \pm 0.2$ & $76 \pm 23$ & - & $51 \pm 1$ \\
\hline
\end{tabular}
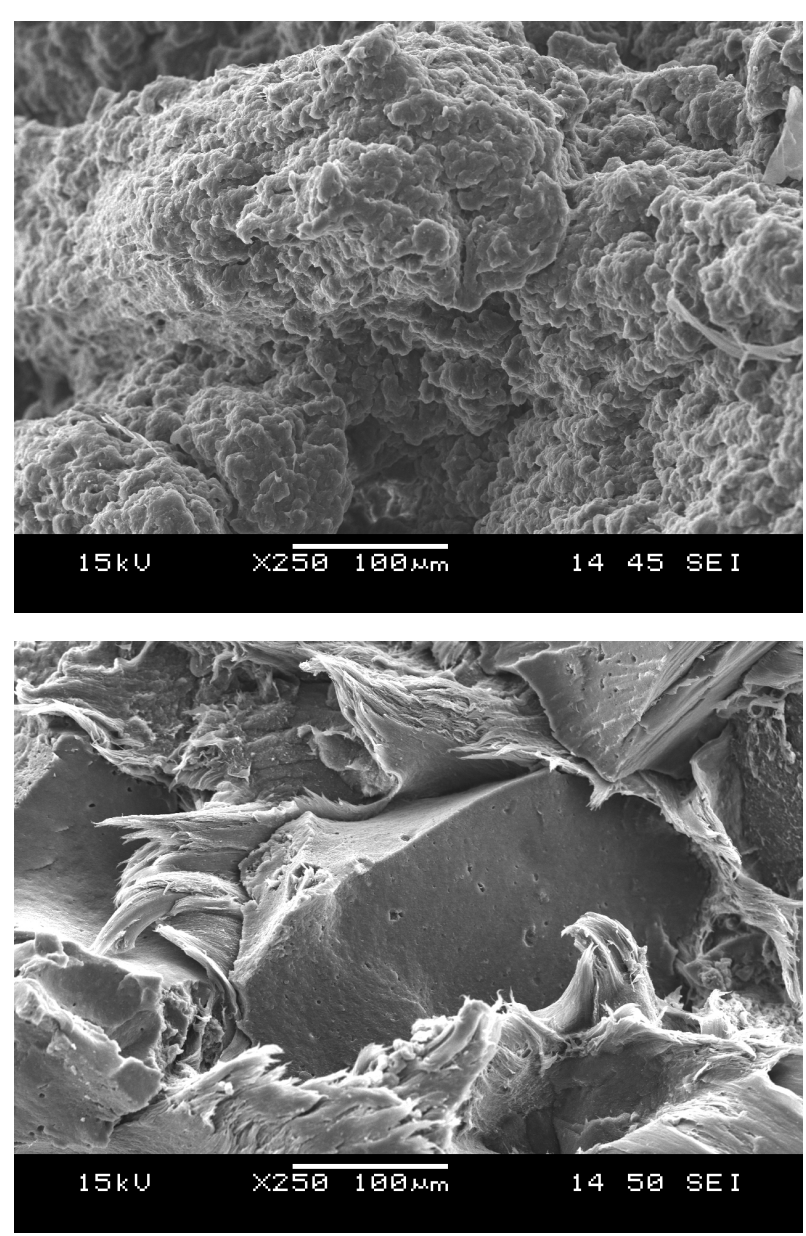

Fig. 6 SEM micrographs of the fracture surfaces of the TDVs 50_R3_S2_120 (a) and 25_R3_S2_120_25uCR (b)

\section{Acknowledgments}

This work was supported by the National Research, Development and Innovation Office, Hungary (OTKA K115949) and by the Higher Education Excellence Program of the Ministry of Human Capacities in the framework of the Nanotechnology research area of the Budapest University of Technology and Economics (BME FIKP-NANO). 


\section{References}

[1] Karger-Kocsis, J., Mészáros, L., Bárány, T. "Ground tyre rubber (GTR) in thermoplastics, thermosets, and rubbers", Journal of Materials Science, 48(1), pp. 1-38, 2013.

https://doi.org/10.1007/s10853-012-6564-2

[2] Abang Ismawi Hassim, D. H., Abraham, F., Summerscales, J., Brown, P. "The effect of interface morphology in waste tyre rubber powder filled elastomeric matrices on the tear and abrasion resistance", Express Polymer Letters, 13(3), pp. 248-260, 2019. https://doi.org/10.3144/expresspolymlett.2019.21

[3] Karger-Kocsis, J. "Polypropylene: Structure, blends and composites - Copolymers and blends", Chapman and Hall Inc., London, United Kingdom, 1995.

https://doi.org/10.1007/978-94-011-0521-7

[4] Karger-Kocsis, J. "Thermoplastic dynamic vulcanizates", In: Karger-Kocsis, J. (eds.) Polypropylene. Polymer Science and Technology Series, Vol. 2., Springer, Dordrecht, The Netherlands, 1999 , pp. 853-858.

https://doi.org/10.1007/978-94-011-4421-6_116

[5] Coran, A. Y., Patel, R. "Rubber-Thermoplastic Compositions. Part IV. Thermoplastic Vulcanizates from Various RubberPlastic Combinations", Rubber Chemistry and Technology, 54(4), pp. 892-903, 1981.

https://doi.org/10.5254/1.3535842

[6] Coran, A. Y., Patel, R. P., Williams, D. "Rubber-Thermoplastic Compositions. Part V. Selecting Polymers for Thermoplastic Vulcanizates", Rubber Chemistry and Technology, 55(1), pp. 116-136, 1982.

https://doi.org/10.5254/1.3535861

[7] Radheshkumar, C., Karger-Kocsis, J. "Thermoplastic dynamic vulcanisates containing LDPE, rubber, and thermochemically reclaimed ground tyre rubber", Plastics, Rubber and Composites, 31(3), pp. 99-105, 2002.

https://doi.org/10.1179/146580102225003074

[8] Radhesh Kumar, C., Fuhrmann, I., Karger-Kocsis, J. "LDPE-based thermoplastic elastomers containing ground tire rubber with and without dynamic curing", Polymer Degradation and Stability, 76(1), pp. 137-144, 2002.

https://doi.org/10.1016/S0141-3910(02)00007-1

[9] Rezaei Abadchi, M., Jalali Arani, A., Nazockdast, H. "Partial replacement of NR by GTR in thermoplastic elastomer based on LLDPE/NR through using reactive blending: Its effects on morphology, rheological, and mechanical properties", Journal of Applied Polymer Science, 115(4), pp. 2416-2422, 2010.

https://doi.org/10.1002/app.31356
[10] Cañavate, J., Casas, P., Colom, X., Nogués, F. "Formulations for thermoplastic vulcanizates based on high density polyethylene, ethylene-propylene-diene monomer, and ground tyre rubber", Journal of Composite Materials, 45(11), pp. 1189-1200, 2011. https://doi.org/10.1177/0021998310369596

[11] Hernández Gámez, J. F., Hernández, E. H., Narro Céspedes, R. I., Neira Velázquez, M. G., Solís Rosales, S. G., Soriano Corral, F., González Morones, P., Fernández Tavizón, S., Díaz De Leon, R., Farías Cepeda, L. "Mechanical reinforcement of thermoplastic vulcanizates using ground tyre rubber modified with sulfuric acid", Polymer Composites, 39(1), pp. 229-237, 2018.

https://doi.org/10.1002/pc.23922

[12] de Sousa, F. D. B., Scuracchio, C. H., Hu, G. H., Hoppe, S. "Effects of processing parameters on the properties of microwave-devulcanized ground tire rubber/polyethylene dynamically revulcanized blends", Journal of Applied Polymer Science, 133(23), Article ID 43503, 2016. https://doi.org/10.1002/app.43503

[13] Zhang, S. L., Xin, Z. X., Zhang, Z. X., Kim, J. K. "Characterization of the properties of thermoplastic elastomers containing waste rubber tire powder", Waste Management, 29(5), pp. 1480-1485, 2009. https://doi.org/10.1016/j.wasman.2008.10.004

[14] Magioli, M., Sirqueira, A. S., Soares, B. G. "The effect of dynamic vulcanization on the mechanical, dynamic mechanical and fatigue properties of TPV based on polypropylene and ground tire rubber", Polymer Testing, 29(7), pp. 840-848, 2010. https://doi.org/10.1016/j.polymertesting.2010.07.008

[15] de Sousa, F. D. B., Scuracchio, C. H., Hu, G.-H., Hoppe, S. "Devulcanization of waste tire rubber by microwaves", Polymer Degradation and Stability, 138, pp. 169-181, 2017. https://doi.org/10.1016/j.polymdegradstab.2017.03.008

[16] de Sousa, F. D. B., Zanchet, A., Scuracchio, C. H. "Influence of reversion in compounds containing recycled natural rubber: In search of sustainable processing", Journal of Applied Polymer Science, 134(41), Article ID: 45325, 2017. https://doi.org/10.1002/app.45325

[17] Berki, P., Karger-Kocsis, J. "Comparative Properties of StyreneButadiene Rubbers (SBR) Containing Pyrolytic Carbon Black, Conventional Carbon Black, and Organoclay", Journal of Macromolecular Science, Part B, 55(7), pp. 749-763, 2016. https://doi.org/10.1080/00222348.2016.1197511 